\section{$\approx$ \#SGS}

science for a changing world

Abstract

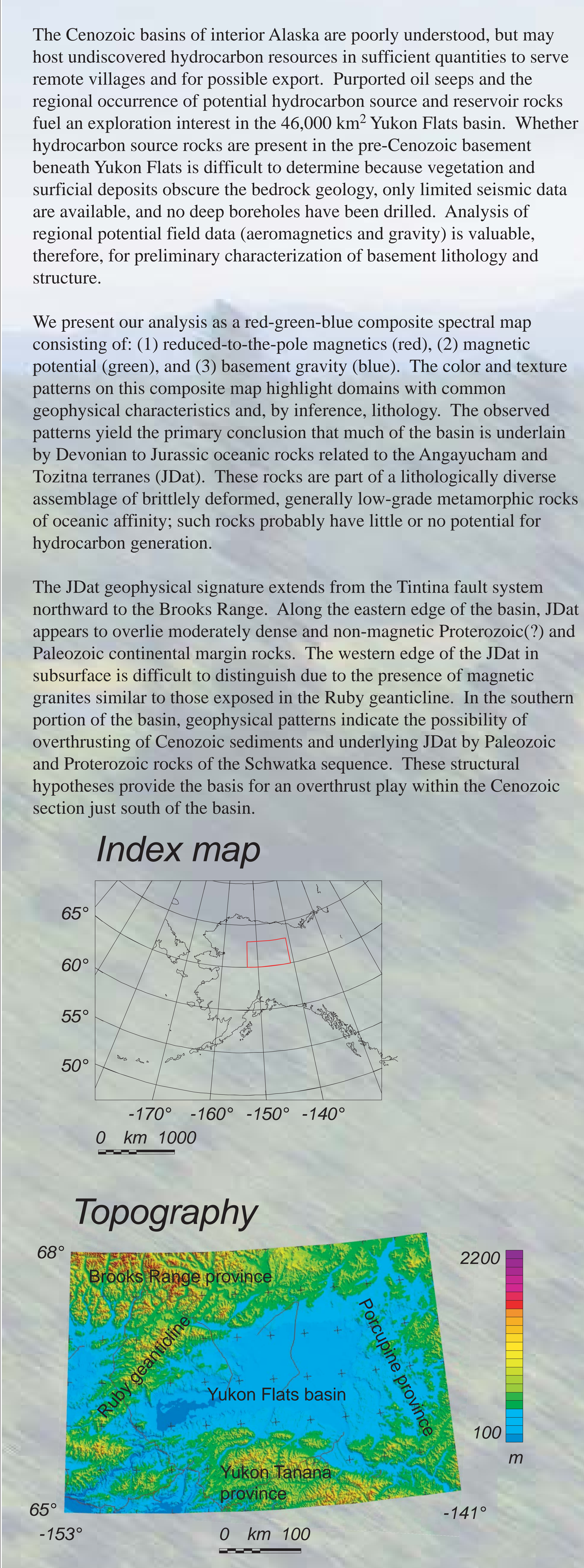

Geophysical Characterization of Pre-Cenozoic Basement for Hydrocarbon Assessment, Yukon Flats, Alaska

By R.W. Saltus ${ }^{1}$ (saltus@usgs.gov), J.D. Phillips ${ }^{1}$ (jeff@usgs.gov), R.G.

Stanley2 (rstanley@usgs.gov), A. Till3 (atill@usgs.gov), and R.L. Morin² (morin@usgs.gov)

${ }^{1}$ Denver, Colorado ${ }^{2}$ Menlo Park, California, ${ }^{3}$ Anchorage, Alaska USGS Open-File Report 2007-1208
GEOLOGIC UNITS
UNIS PRESENTI MORE The
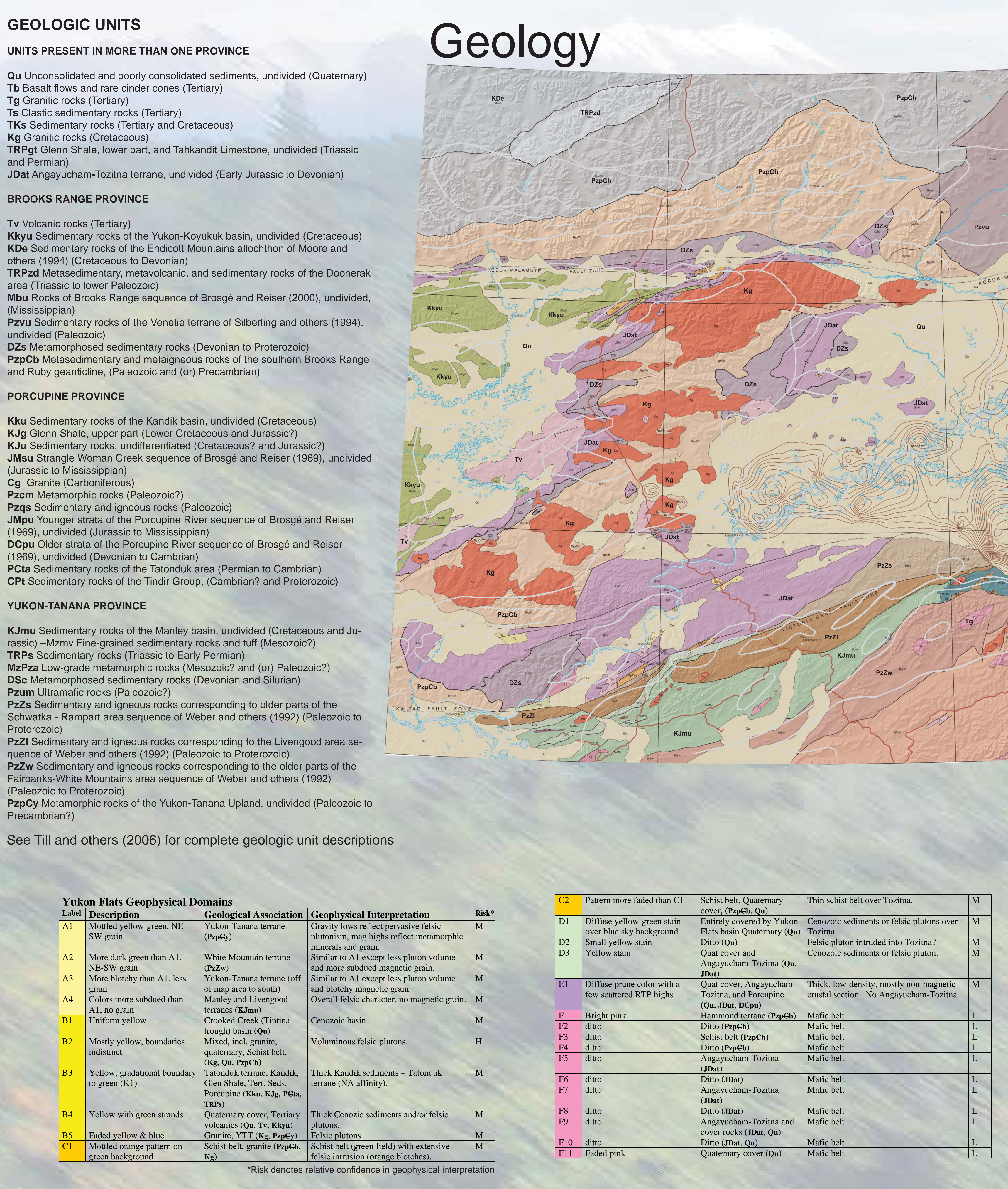

Reduced-to-pole Aeromagnetics

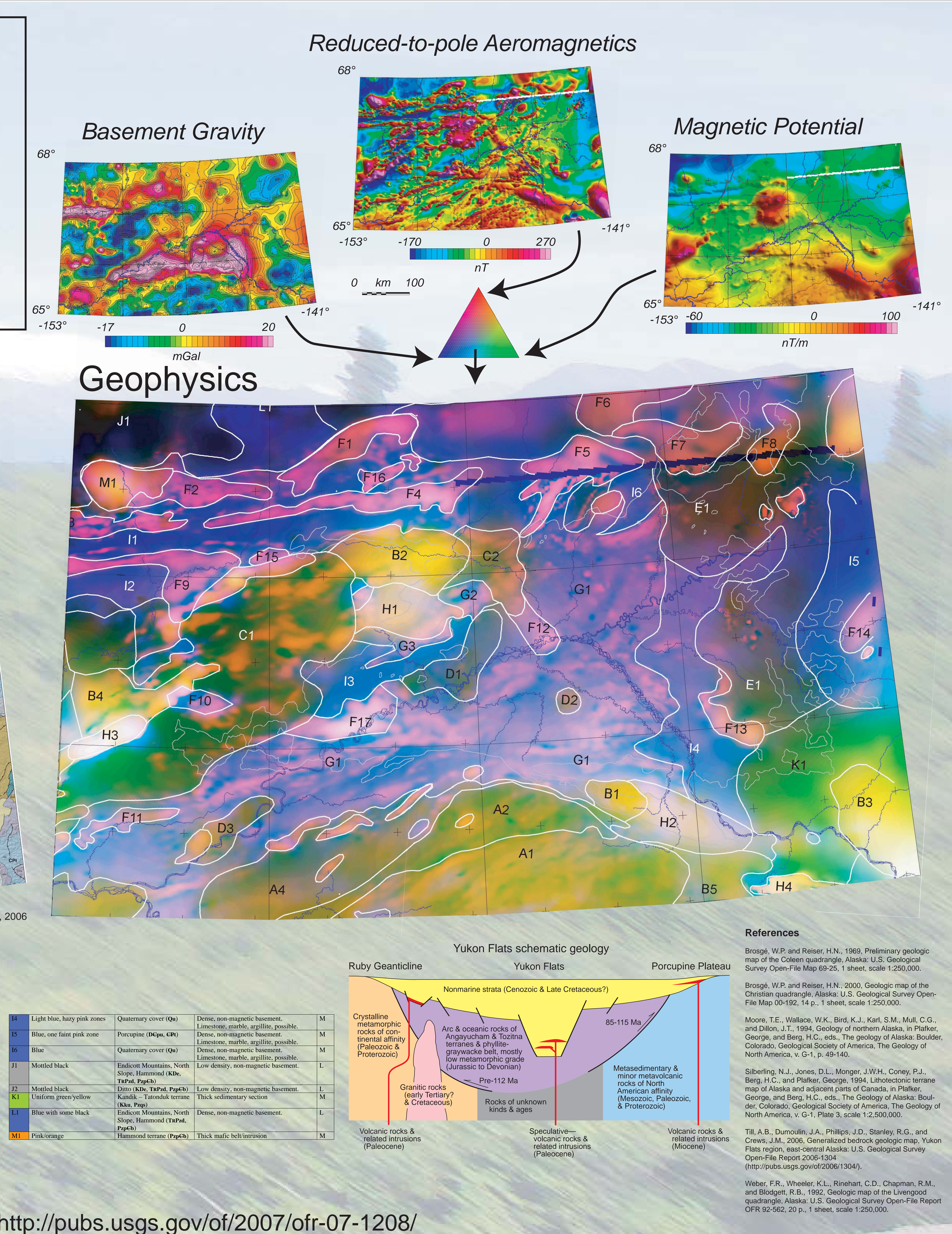

http://pubs.usgs.gov/of/2007/ofr-07-1208/ 